\title{
A RELAÇÃO PÚBLICO-PRIVADO E A GESTÃO DO TRABALHO NAS FUNDAÇÕES ESTATAIS DE SAÚDE
}

\author{
THE PUBLIC-PRIVATE RELATIONSHIP AND THE MANAGEMENT \\ OF WORK IN STATE HEALTH FOUNDATIONS
}
Reneide Muniz da Silva' (iD [0000-0001-9587-4103], Isabella Chagas Samico² (iD) [0000-0002-8338-7946], Pedro Miguel dos Santos Neto ${ }^{3}$ (D) [0000-0001-5665-0924]

\author{
' Faculdade Pernambucana de Saúde, Coordenação do Curso de Enfermagem, Recife, Pernambuco, \\ Brasil.<reneide@fps.edu.br> \\ ${ }^{2}$ Instituto de Medicina Integral Prof. Fernando Figueira, Grupo de Estudos de Avaliação e Gestão em \\ Saúde, Recife, Pernambuco, Brasil. \\ ${ }^{3}$ Fundação Oswaldo Cruz,Centro de Pesquisa Aggeu Magalhães, Departamento de Saúde Coletiva, \\ Recife, Pernambuco, Brasil.
}

Resumo As discussões sobre a relação público-privado atentam para a necessidade de imprimir à gestão pública maior autonomia, agilidade e flexibilidade gerenciais e administrativas em setores estratégicos do sistema de saúde. A pesquisa qualitativa que deu origem a este artigo objetivou analisar a gestão do trabalho na Fundação Estatal de Saúde da Família da Bahia e na Fundação Estadual de Saúde de Sergipe, usando técnica de triangulação de dados e análise hermenêuticadialética. Participaram gestores, trabalhadores e usuários dos dois estados, totalizando vinte entrevistas semiestruturadas. Os fatores contextuais e os atores foram analisados utilizando-se um modelo que enfatizou as dimensões do macro e do microcontexto. $\mathrm{O}$ desempenho satisfatório relativo à gestão do trabalho pode ser atribuído à variedade e complexidade de fatores enfrentados pela administração direta. A inter-relação do microcontexto com subdimensões do macrocontexto contribuiu favoravelmente para a implementação das fundações. Como contribuição aos gestores, construiu-se um quadro contendo indicadores para o monitoramento das atribuições da gestão do trabalho nas fundações estatais. Os resultados e potencialidades dessas experiências podem auxiliar no enfrentamento dos desafios à gestão em saúde, dotando-a de maior efetividade, celeridade e resolubilidade na atenção à saúde e na gestão do trabalho no Sistema Único de Saúde.

Palavras-chave gestão em saúde; recursos humanos em saúde; administração pública; parceria público-privado.
Abstract The discussions on the public-private relationship highlight the need to provide public management with more managerial and administrative autonomy, agility and flexibility in strategic sectors of the health care system. The qualitative research that was the origin of the present article had the aim of analyzing the work management at the State-Owned Family Health Foundation of Bahia (Fundação Estatal de Saúde da Família da Bahia, in Portuguese) and at the State Health Foundation of Sergipe (Fundação Estadual de Saúde de Sergipe, in Portuguese), using the technique of data triangulation and hermeneutic-dialectical analysis. Managers, workers and users from both states took part in the study, totaling twenty semi-structured interviews. The contextual factors and the actors were analyzed using a model that emphasized the dimensions of the macroand microcontexts. The satisfactory performance regarding work management may be attributed to the variety and complexity of the factors faced by the direct administration. The interrelationship of the microcontext with subdimensions of the macrocontext contributed favorably to the implementation of the foundations. As contributions to the managers, we developed a table containing indicators for the monitoring of the attributions of the work management at the state-owned foundations. The results and potentialities of these experiences may help face the challenges to management in health, providing it with more efficacy, speed and solvability in health care and work management in the Brazilian Unified Health System.

Keywords management in health; human resources in health; public administration; public-private partnership. 


\section{Introdução}

A implementação de políticas públicas se depara com entraves concernentes à capacidadedegovernopelosgestores públicos, diantedaexigênciadoprocesso demodernizaçãodoEstado.Destacam-sediversosproblemas, entreelesacarência ou insuficiência de infraestrutura, as limitações na reorganização dos sistemas de serviços e a inadequação dos instrumentos de gestão existentes (Brasil, 2006; Abrucio, 2005).

Observa-se crescente utilização de uma variedade de modalidades de gestão pública, mesmo com a escassez de estudos e avaliação sobre a pertinência, a efetividade e a eficácia de tais experiências. Posturas contrárias, como as observadas por segmentos de trabalhadores e conselhos de saúde, afirmam que os 'novos modelos de gestão' fazem parte de uma estratégia de contrarreforma do Estado "flexibilizando a gestão e os direitos sociais e trabalhistas, e privatizando o que é público" (Correia, 2011, p. 48). As posições em favor asseveram o seu potencial de imprimir maior agilidade, autonomia gerencial e otimização dos gastos na direção de modernização da gestão pública, visando cumprir com sua missão de ofertar ações e serviços de saúde de qualidade à população sob sua responsabilidade (Vecina Neto, 2009; Barboza, 2009).

Ao focalizar os delineamentos das reformas do aparelho de Estado (Torres, 2008; Costa, 2006; Bresser-Pereira, 2010; Nogueira, 2010) nos anos 1990, encontravam-se no cenário político brasileiro os debates sobre a elaboração do Plano Diretor da Reforma do Aparelho de Estado (PDRAE), estabelecendo, em essência, as bases para implementar a nomeada administração gerencial em resposta ao debilitado modelo burocrático (Lamarca, 2009; Brasil, 1967). Em 1998, foi aprovada a emenda constitucional n. 19, respaldando legalmente a implantação das mudanças na administração pública brasileira (Brasil, 1998). Dentre as diretrizes preconizadas pela Reforma e definidas no Plano, encontravam-se a flexibilização para auferir maior autonomia aos gestores públicos na administração dos recursos humanos, materiais e financeiros; e a transferência para organizações públicas não estatais de atividades não exclusivas do Estado, notadamente nas áreas de saúde, educação, cultura, ciência e tecnologia e meio ambiente. Em suma, a reforma gerencial visava à redefinição do papel do Estado, que deixava de ser o responsável direto pelo desenvolvimento econômico e social para assumir mais enfaticamente a função de Estado regulador (Bagattolli, 2009).

A gestão pública em saúde no Brasil vem demandando soluções e alternativas para múltiplos problemas enfrentados pelos gestores públicos, em especial no que tange ao desenvolvimento do processo de regionalização e instituição do decreto n. 7.508/11, como estratégias de organização do sistema, e à integralidade na atenção à saúde (Santos, N., 2010). Assim, a gestão pública da saúde, situada na dimensão da organização de ações e serviços públicos em um sistema, coloca em pauta novamente a discussão do papel do Estado e a frustração das 
expectativas dos cidadãos quanto à adequação, à eficiência e à suficiência dos serviços estatais (Brasil, 2006; Santos, L., 2010). Exige, portanto, um processo de articulação institucional com os demais entes públicos e outros parceiros, buscando promover e assegurar condições políticas de governabilidade (Franzese, 2010).

Além do exercício de uma relação mais solidária entre os gestores, melhor definição do papel da esfera estadual, redefinição da lógica de transferência de recursos, adequação do arcabouço legal às necessidades atuais do sistema, o aprimoramento do processo de regionalização e a adoção de modelos de gestão inovadores são algumas das exigências a serem enfrentadas (Brasil, 2006). O Sistema Único de Saúde (SUS), como um modelo que demanda negociações, consensos e compartilhamento de responsabilidades, imprime novos padrões à gestão pública e à organização e oferta de serviços públicos. Os pactos interfederativos e as redes de serviços intra e interfederativas são formas de gestão compartilhada que se desenvolvem tanto entre entes públicos como entre estes e os privados (Santos, L., 2010).

As discussões sobre a relação público-privado e a necessidade de imprimir à gestão pública maior autonomia, agilidade e flexibilidade gerenciais e administrativas em setores estratégicos do SUS atentam para o ressurgimento do debate sobre a criação de novas modalidades de gestão pública em saúde, entre as quais estão as fundações públicas de direito privado. Ressalta-se que a assunção por quaisquer das novas formas de gestão não devem comprometer nem alterar os propósitos do SUS (Andrade, 2009; Heimann et al., 2010; Müller Neto, 2002; Cebes, 2010).

A ampliação da oferta de serviços e qualidade do atendimento, afiançando o acesso em consonância com o conjunto das necessidades dos cidadãos (universalidade e integralidade), a autonomia e flexibilização administrativa e financeira, assim como a gestão de pessoal, são alguns dos fundamentos das propostas e discussões sobre os novos modelos de gestão pública em saúde (Unesco, 2008). As contestações envolvendo as organizações sociais de saúde, como o questionamento em relação à constitucionalidade e à sua capacidade administrativa, e também aos consócios referentes às dificuldades de transferência de recursos próprios para outras organizações, evidenciaram a necessidade da implementação de outros modelos institucionais de gestão pública, sendo então admitida a opção pelas fundações públicas de direito privado (Andrade, 2009). Contudo, nesse cenário, entre os principais opositores estão os conselhos de saúde e as entidades representativas de trabalhadores da saúde, o que tem motivado uma série de conflitos entre gestores e conselhos, sobretudo nos estados e municípios onde as organizações sociais de saúde e as fundações estatais estão implantadas ou em processo de implantação (Bresser-Pereira, 2010; Andrade, 2009; Fontes, 2009).

A despeito das dissensões que circundam os debates sobre as alternativas institucionais de gestão pública, os gestores da saúde vêm atuando como protagonistas na implantação de alternativas diversas de gestão, amparados pela Constituição Federal de 1988 e em leis complementares, como nos casos de 
Minas Gerais e Mato Grosso com os consócios; de São Paulo e Pernambuco com as organizações sociais de saúde; e de Sergipe, Bahia e Rio de Janeiro com as fundações estatais. Algumas dessas iniciativas, em última instância, visam ao fortalecimento do papel do Estado para assegurar a lógica de complementaridade do sistema e a continuidade do cuidado pelos serviços de saúde, garantindo não só a dimensão assistencial como também a econômica, pela obtenção de escala e escopo das ações desenvolvidas no âmbito do Estado (Vecina Neto, 2009).

Assim, em alguns estados e municípios foram sancionadas leis autorizando a instituição das fundações públicas de direito privado. Destacam-se o Governo de Sergipe, com a Fundação Estadual de Saúde (Funesa) e duas fundações hospitalares; o Governo do Estado da Bahia, com a Fundação Estatal de Saúde da Família (Fesf) e a Fundação Estatal para Administração Hospitalar; e ainda o Estado do Rio de Janeiro, com as fundações estatais de hospitais e os institutos de saúde. Em sua maioria, as leis complementares para criação dessas fundações resguardam os princípios que definem a instituição de fundações estatais de direito privado vinculadas à administração indireta para execução de atividades sem fins lucrativos e não exclusivas do Estado, como as da área da saúde (Andrade, 2009; Fontes, 2009; Brasil, 2007; Sergipe, 2008a, 2008b, 2008c, 2008d; Bahia, 2009a, 2009b; Rio de Janeiro, 2007; Picchiai e Junqueira, 2009; Silva, 2005).

A fundação pública de direito privado ou fundação estatal (FE) é caracterizada como um instituto público para prestação de serviços sociais de forma direta ao cidadão, em área não exclusiva de atuação do Estado, entre elas saúde, assistência, cultura e desportos. Integra a administração indireta com patrimônio público e inalienável. Vinculada à instância pública de origem da criação, é a responsável direta pela supervisão administrativa. Adota o regime de trabalho celetista, podendo instituir remuneração com base nos valores de mercado, recolher Fundo de Garantia do Tempo de Serviço (FGTS), celebrar acordo coletivo e incentivo por produtividade. Observa as regras do direito público quanto à realização de concurso público e demissão motivada (Andrade, 2009).

Com base nos pressupostos legais e operacionais referidos anteriormente, em 2008 o estado de Sergipe, em um contexto de reorganização do sistema estadual de saúde por meio da instituição de uma reforma sanitária e gerencial, criou a Fundação Estadual de Saúde para prestação de serviços de saúde em áreas consideradas críticas e prioritárias para a organização do sistema, como estratégias de viabilização operacional da reforma, com o entendimento de que apenas a administração pública direta não seria suficiente para responder aos desafios impostos pelo sistema. Portanto, tendo por finalidade "prestar serviços de saúde de atenção básica, de promoção, prevenção e proteção da saúde coletiva e individual, de formação profissional e educação 
permanente na área de saúde pública", foi sancionada a lei n. 6.348/2008, criando a Fundação Estadual de Saúde (Sergipe, 2008c, p. 2).

A instituição da Fesf em 2007 pelo estado da Bahia, por meio da promulgação da lei complementar n. 29, nasceu da necessidade de se responder aos problemas enfrentados pela Estratégia Saúde da Família concernentes à precarização dos vínculos trabalhistas, entraves no provimento e fixação dos profissionais, além da incapacidade de formação e qualificação, que ocasionava deformidades na execução das ações da referida estratégia (Andrade, 2009).

No âmbito do SUS, a gestão de pessoal da administração pública direta é largamente mencionada como principal fator de dificuldade da prestação de serviços com a qualidade e a agilidade exigidas. A incorporação de profissionais e especialistas na quantidade e na diversidade necessárias, com remuneração mais justa, encontra barreiras impostas tanto pela Lei de Responsabilidade Fiscal como pela falta de autonomia orçamentária e financeira a que estão submetidos os serviços de saúde (Bresser-Pereira, 2010) e as iniciativas de reorganização do modelo de atenção à saúde, como no caso da Estratégia Saúde da Família.

Situar as discussões no sentido da adoção de um modelo em que se obtenha maior autonomia e flexibilidade de gestão, particularmente na contratação e no gerenciamento de pessoal (Vecina Neto, 2009; Santos, L., 2010; Andrade, 2009; Unesco, 2008; Fontes, 2009), demanda esforço e priorização por parte dos gestores públicos de saúde, teóricos e acadêmicos que prezam pela consolidação e qualificação do SUS, diante da complexidade e das mudanças do tempo presente e futuro do setor e das relações público-privadas na área de saúde.

Nesse contexto, objetivou-se analisar a gestão do trabalho na Fesf/Bahia e na Funesa/Sergipe.

\section{Percurso metodológico}

Optou-se pela utilização da abordagem de pesquisa qualitativa para explicar aspossíveis transformaçõesocorridasaolongo dotempoeaidentificaçãodos fatorescontextuais que influenciaram naimplementação dagestão dotrabaIho das referidas fundações.

Na análise do contexto de implantação das fundações, foi aplicada a técnica de triangulação de dados por meio da realização de entrevistas semiestruturadas com atores-chaves para a implantação das fundações nos respectivos estados, análise documental e a observação não participante (Yin, 2005).

Como unidades de análise para explicação da implantação, consideraram-se os processos organizacionais e os comportamentos dos dirigentes e profissionais em cada uma das fundações estudadas; e ainda a incorporação dos gestores e profissionais envolvidos com a implantação das fundações nas secretarias estaduais de saúde da Bahia e de Sergipe. 
Definiu-se a participação de atores com perfil e posição estratégica para os objetivos do estudo (Quadro 1). A seleção procurou contemplar o afirmado por Champagne e colaboradores (2011), em que os atores em dado momento e contexto, com suas características, práticas, intenções, interesses e convicções, desempenham papéis indispensáveis em qualquer intervenção e são, em última instância, os responsáveis pela transformação, moldagem ou insucesso da intervenção. Quadro 1.

\begin{tabular}{|c|c|c|}
\hline Perfil dos atores envolvidos na im & henta & o das fundações \\
\hline Perfil dos atores & No & Posição \\
\hline \multirow{4}{*}{ Gestores } & 2 & Secretário estadual de saúde \\
\hline & 2 & $\begin{array}{l}\text { Secretário municipal de saúde (presidente do Conselho de Secretarias } \\
\text { Municipais de Saúde/Cosems) }\end{array}$ \\
\hline & 2 & Contrato (gestor do contrato na Secretaria Estadual de Saúde) \\
\hline & 3 & $\begin{array}{l}\text { Federal (secretários do Ministério da Saúde; diretor do Ministério de } \\
\text { Planejamento, Orçamento e Gestão) }\end{array}$ \\
\hline Dirigentes & 2 & Diretor geral da fundação estatal \\
\hline Órgãos de controle & 3 & Ministério Público Estadual e Controladoria Geral do Estado \\
\hline \multirow[b]{2}{*}{ Representantes de trabalhadores } & 2 & Conselho Estadual de Saúde \\
\hline & 2 & Fundação estatal \\
\hline Representantes de usuários & 2 & Conselho Estadual de Saúde \\
\hline Total & 20 & \\
\hline
\end{tabular}

Para a análise da influência dos fatores contextuais e dos atores, foi utilizado o modelo proposto por Araújo Jr. e Maciel Filho (2001), focalizando as dimensões do macro e do microcontexto (Quadro 2).

Quadro 2.

Modelo de análise do macro e do microcontexto

\begin{tabular}{|c|c|c|c|c|c|}
\hline \multicolumn{3}{|c|}{ MACROCONTEXTO } & \multicolumn{3}{|c|}{ MICROCONTEXTO } \\
\hline Esfera política & Esfera econômica & Esfera social & $\begin{array}{l}\text { Política } \\
\text { setorial }\end{array}$ & $\begin{array}{l}\text { Finanças } \\
\text { setoriais }\end{array}$ & $\begin{array}{l}\text { Problemas } \\
\text { de saúde e } \\
\text { serviços }\end{array}$ \\
\hline $\begin{array}{l}\text { Mudanças } \\
\text { políticas }\end{array}$ & $\begin{array}{l}\text { Tamanho e } \\
\text { condições da } \\
\text { economia }\end{array}$ & $\begin{array}{l}\text { Mudanças } \\
\text { demográficas }\end{array}$ & $\begin{array}{l}\text { Principais } \\
\text { interesses }\end{array}$ & $\begin{array}{l}\text { Orçamento e } \\
\text { gastos da saúde }\end{array}$ & $\begin{array}{l}\text { Mudanças } \\
\text { epidemiológicas }\end{array}$ \\
\hline Regime político & $\begin{array}{l}\text { Mudanças na } \\
\text { economia }\end{array}$ & Qualidade de vida & $\begin{array}{l}\text { Poder } \\
\text { dentro do } \\
\text { setor }\end{array}$ & $\begin{array}{l}\text { Políticas e } \\
\text { mecanismos de } \\
\text { financiamento }\end{array}$ & $\begin{array}{l}\text { Principais } \\
\text { problemas de } \\
\text { saúde }\end{array}$ \\
\hline Ideologias & $\begin{array}{l}\text { Políticas } \\
\text { econômicas e } \\
\text { financeiras }\end{array}$ & Pobreza & $\begin{array}{l}\text { Políticas de } \\
\text { saúde }\end{array}$ & & $\begin{array}{l}\text { Recursos } \\
\text { humanos }\end{array}$ \\
\hline $\begin{array}{l}\text { Políticas públicas } \\
\text { Influências } \\
\text { internacionais }\end{array}$ & Gastos públicos & $\begin{array}{l}\text { Distribuição } \\
\text { de renda e } \\
\text { disparidades } \\
\text { Desenvolvimento } \\
\text { humano }\end{array}$ & $\begin{array}{l}\text { Relação } \\
\text { entre os } \\
\text { setores } \\
\text { público e } \\
\text { privado }\end{array}$ & $\begin{array}{l}\text { Fontes e } \\
\text { volume de } \\
\text { recursos }\end{array}$ & $\begin{array}{l}\text { Rede de serviços } \\
\text { de saúde }\end{array}$ \\
\hline
\end{tabular}

Fonte: Araújo Jr. e Maciel Filho, 2001. 
No presente estudo, os governos estaduais da Bahia e de Sergipe compuseram o macrocontexto de análise dos fatores políticos, econômicos e sociais, sendo observados aspectos como conjuntura partidária dos governos, conflitos, mobilização de movimentos sociais, condições econômicas de crescimento, crises ou cortes e mudanças demográficas, ou seja, situações presentes na época da implantação das fundações. De outro modo, as secretarias de saúde, a política setorial de saúde, o financiamento do setor e os problemas e serviços de saúde constituíram o microcontexto no qual foram analisadas circunstâncias como as mudanças epidemiológicas, os gastos com saúde e a disponibilidade de recursos humanos, entre outras (Araújo Jr. e Maciel Filho, 2001; Lyra, 2009). A análise da posição dos atores foi complementada pelo referencial do Planejamento Estratégico Situacional (PES) de Carlos Matus (1996), no qual a participação dos atores assume diferentes posições ou interesses - apoio, rejeição ou indiferença - atribuindo valores diferenciados diante de certo projeto.

As informações obtidas nas entrevistas foram interpretadas utilizandose a técnica de análise da hermenêutica-dialética, almejando a compreensão simbólica da mensagem contextualizada e seu entendimento quanto à orientação e modificação da ação em dada realidade (Minayo, 2004; 2012). Operacionalmente, seguiram-se os passos propostos por Minayo (2012) para interpretação, com base em um trabalho cuidadoso de exploração e triangulação das informações recolhidas em entrevistas, documentos, observações e diário de campo visando aumentar a confiabilidade do estudo: ordenação dos dados; classificação dos dados; e análise final. Como recurso didático, a Figura 1 apresenta um fluxograma do desenvolvimento operacional da análise dialética elaborado por Assis e Jorge (2010). O material examinado em detalhe permitiu obter um quadro sintético de representações, a identificação de temas relevantes e a compreensão final e provisória como resultado das etapas antecedentes (Minayo, 2004; 2012).

Seguiu-se a 'ordenação dos dados' (Minayo, 2004; 2012), obtida a partir da organização e leitura de documentos teóricos e institucionais, das anotações do diário de campo, da observação não participante em reuniões e eventos sobre a fundação estatal e das transcrições das entrevistas. A 'classificação' (Minayo, 2004; 2012) do material consistiu de nova leitura das transcrições, durante a qual os relatos foram organizados em cinco subconjuntos dos atoreschaves e selecionadas as 'estruturas de relevância ou núcleos de sentido', o que se conseguiu por meio da comparação de semelhanças, divergências ou complementaridade de ideias e posições dos sujeitos (Minayo, 2012). 
Figura 1.

Fluxograma de desenvolvimento da análise hermenêutica dialética

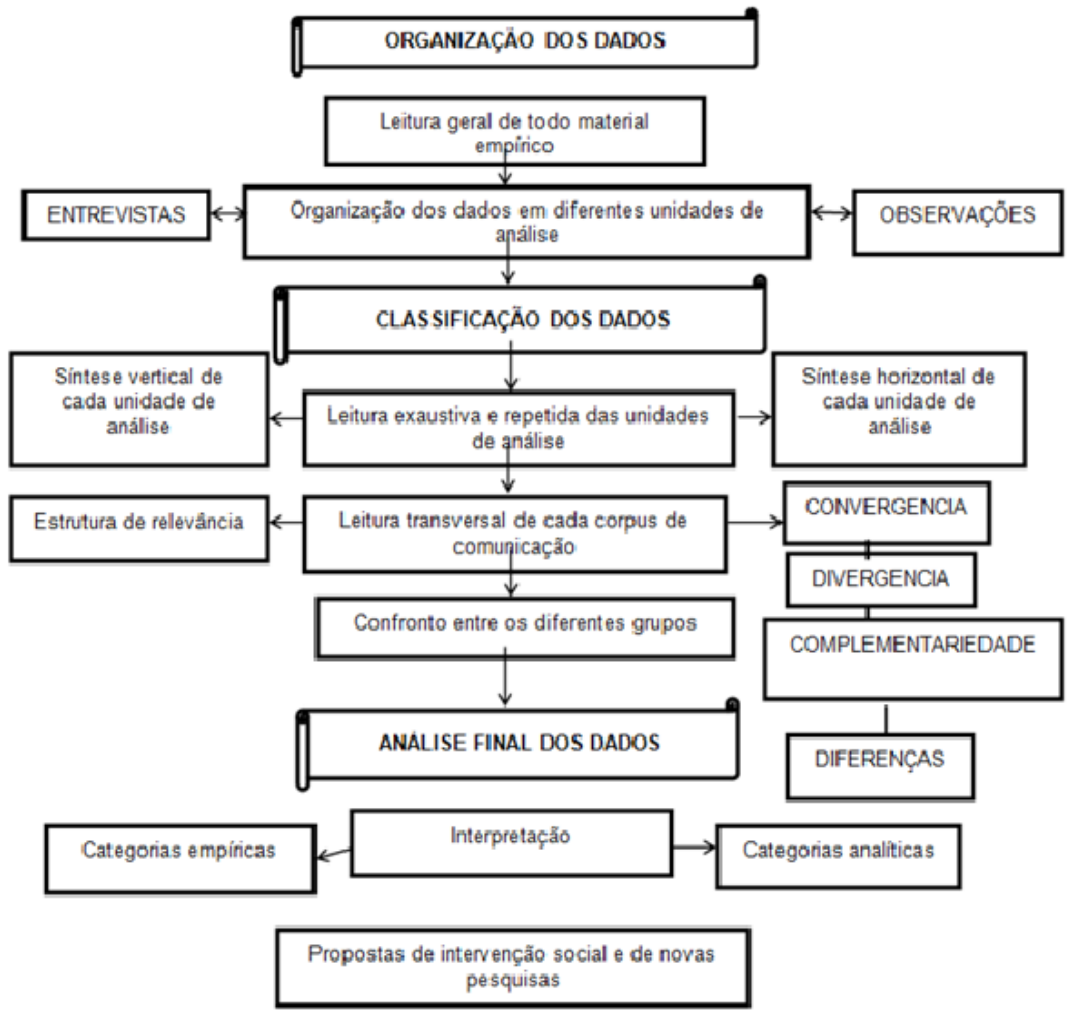

Figura 1 - Fluxograma de desenvolvimento da análise hermenêutica dialética. Fonte: Assis e Jorge, 2010

Dessa forma, os subconjuntos foram identificados como: Subconjunto Gestores (SCG), E1 a E9; Subconjunto Dirigentes de Fundações (SCD), E10 e E11; Subconjunto Órgãos de Controle (SCOC), E12 a E14; Subconjunto Trabalhadores (SCT), E15 a E18; e Subconjunto Usuários (SCU), E19 e E20. Importante ressaltar que a estrutura de relevância 'dificuldades/melhorias na gestão do trabalho' surgiu em todos os subconjuntos.

A análise final (Minayo, 2004; 2012) permeou todos os passos anteriores, conformando uma síntese provisória impregnada pela visão de mundo da pesquisadora e pela dificuldade de interpretação de um objeto novo e carregado de conflito por sua inserção em área complexa e historicamente determinada, como a da gestão pública de saúde.

A pesquisa foi aprovada pelo Comitê de Ética em Pesquisa em Seres Humanos do Instituto de Medicina Integral Prof. Fernando Figueira (Imip), parecer n. 247.820, de 17 de abril de 2013. 


\section{A gestão do trabalho na fundação estatal}

A área de gestão do trabalho pode ser considerada como um dos setores mais críticos do SUS, expondo o conflito entre as exigências da Lei de Responsabilidade Fiscal e as garantias da Lei Orgânica da Saúde (Picchiai e Junqueira, 2009). Persistem nesse contexto uma baixa autonomia da administração direta quanto ao gerenciamento das relações de trabalho, a reduzida capacidade de regulação do sistema e de controle dos processos de contratação, demissão, remuneração, formação e educação permanente em saúde.

Observa-se como exigência legal a incorporação, na própria lei complementar que autoriza a instituição das fundações estatais, dos requisitos para gestão do trabalho, devendo o regimento interno e o estatuto normatizarem as regras para cumprimento dos requisitos (Bahia, 2009a, 2009b; Sergipe, 2008d; Rio de Janeiro, 2007).

Para Andrade (2009), a criação da fundação estatal na Bahia decorreu da necessidade de se responder aos problemas da Estratégia Saúde da Família concernentes à precarização dos vínculos trabalhistas, entraves no provimento e fixação dos profissionais, e à incapacidade de formação e qualificação, que ocasionam deformidades na execução das ações da referida estratégia - problemas vivenciados pela maioria dos municípios brasileiros. Portanto, atribui-se como pressupostos para o funcionamento das fundações estatais a organização da gestão do trabalho com base em atributos e indicadores da forma de acesso por meio de concurso público e demissão motivada, a implantação de plano de desenvolvimento de pessoal, plano de carreira e salário, remuneração compatível com o praticado no mercado, com base em critérios de desempenho e qualidade, instituição de data base das categorias profissionais para negociação coletiva de trabalho e organização de sistema de banco de dados de pessoal como ferramenta gerencial.

Observa-se desempenho satisfatório relativo aos desafios da gestão do trabalho conferidos às fundações estatais, podendo estar relacionado tanto à variedade $\mathrm{e}$ complexidade de fatores e limitações enfrentadas pela administração direta como pela importância desse elemento para a gestão das ações e serviços de saúde, revelando-se em enfoque prioritário na instituição das fundações. Portanto, a execução das ações de gestão do trabalho foi classificada como avançada tanto na Fesf como na Funesa, alcançando 90\% e 80\%, respectivamente (Tabela 1).

Na Fesf, apenas o atributo 'admissão de pessoal por concurso ou seleção pública e demissão motivada' foi classificado como implantação intermediária (50\%); todos os demais alcançaram 100\% de adequação. Na Funesa, pela ausên-

cia de 'organização de banco de dados de pessoal', este atributo foi o único com 


\section{classificação de 'implantação crítica' (0\%); os restantes conseguiram 'implantação avançada' (100\%) ou 'intermediária' (50\%).}

Tabela 1.

Grau de implantação da gestão do trabalho de acordo com a situação dos atributos e indicadores das fundações estatais de saúde da Bahia e de Sergipe

\begin{tabular}{|c|c|c|c|c|c|}
\hline \multirow{3}{*}{ Atributos e indicadores } & \multirow{3}{*}{$\begin{array}{l}\text { Pontuação } \\
\text { máxima }\end{array}$} & \multicolumn{4}{|c|}{ Pontuação obtida } \\
\hline & & \multicolumn{2}{|c|}{ Fesf/BA } & \multicolumn{2}{|c|}{ Funesa/SE } \\
\hline & & $\mathbf{n}$ & $\%$ & $\mathbf{n}$ & $\%$ \\
\hline $\begin{array}{l}\text { 1. Admissão de pessoal por concurso ou seleção pública e } \\
\text { demissão motivada }\end{array}$ & 20 & 10 & 50 & 10 & 50 \\
\hline a) maior \% de admissão por concurso público & 15 & & & & \\
\hline b) maior \% de admissão por seleção pública & 10 & 10 & & & \\
\hline c) maior \% de contratação temporária & 5 & & & 5 & \\
\hline d) maior \% de demissões com inquérito administrativo & 5 & & & 5 & \\
\hline e) maior \% de demissões sem inquéritos administrativos & 0 & 0 & & & \\
\hline 2. Implantação de plano de desenvolvimento de pessoal & 20 & 20 & 100 & 20 & 100 \\
\hline $\begin{array}{l}\text { a) implantado (atividades de educação permanente e avaliação } \\
\text { de desempenho desenvolvidas) }\end{array}$ & 20 & 20 & & 20 & \\
\hline $\begin{array}{l}\text { b) parcialmente implantado (apenas uma das atividades } \\
\text { previstas) }\end{array}$ & 10 & & & & \\
\hline c) não implantado (nenhuma atividade desenvolvida) & & & & & \\
\hline 3. Implantação de plano de carreira e salários (PCS) & 20 & 20 & 100 & 20 & 100 \\
\hline a) implantado ( $100 \%$ das etapas previstas implantadas) & 20 & 20 & & 20 & \\
\hline b) parcialmente implantado ( $<50 \%$ das etapas implantadas) & 10 & & & & \\
\hline c) não implantado (0 - >50\%) & 0 & & & & \\
\hline $\begin{array}{l}\text { 4. Remuneração de acordo com critérios de desempenho e de } \\
\text { qualidade }\end{array}$ & 20 & 20 & 100 & 20 & 100 \\
\hline a) vinculação da remuneração ao critério de desempenho & 10 & 10 & & 10 & \\
\hline b) vinculação da remuneração ao critério de qualidade & 10 & 10 & & 10 & \\
\hline 5. Instituição de data base das categorias profissionais & 10 & 10 & 100 & 10 & 100 \\
\hline a) instituída & 10 & 10 & & 10 & \\
\hline b) não instituída & 0 & & & & \\
\hline 6. Organização do banco de dados de pessoal & 10 & 10 & 100 & 0 & 0 \\
\hline a) organizado & 5 & 5 & & & \\
\hline b) utilizado como ferramenta gerencial & 5 & 5 & & & \\
\hline c) inexistência de banco de dados & 0 & & & 0 & \\
\hline Total & 100 & 90 & 90 & 80 & 80 \\
\hline
\end{tabular}


Como contribuição aos gestores, o Quadro 3 apresenta indicadores para monitoramento das atribuições sobre gestão do trabalho nas fundações estatais. Quadro 3.

Indicadores de monitoramento das atribuições da gestão do trabalho na fundação estatal

\begin{tabular}{|c|c|}
\hline Atributo & Indicador \\
\hline $\begin{array}{l}\text { 1. Admissão de pessoal por concurso ou seleção pública } \\
\text { e demissão motivada }\end{array}$ & $\begin{array}{l}\text { a) maior \% de admissão por concurso público } \\
\text { b) maior \% de admissão por seleção pública } \\
\text { c) maior \% de contratação temporária } \\
\text { d) maior \% de demissões com inquérito administrativo } \\
\text { e) maior \% de demissões sem inquéritos administrativos }\end{array}$ \\
\hline 2. Plano de desenvolvimento de pessoal & $\begin{array}{l}\text { a) implantado (atividades de educação permanente e } \\
\text { avaliação de desempenho desenvolvidas) } \\
\text { b) parcialmente implantado (apenas uma das atividades } \\
\text { previstas) } \\
\text { c) não implantado (nenhuma atividade desenvolvida) }\end{array}$ \\
\hline 3. Plano de carreira e salários & $\begin{array}{l}\text { a) implantado ( } 100 \% \text { das etapas previstas implantadas) } \\
\text { b) parcialmente implantado ( }<50 \% \text { das etapas implantadas) } \\
\text { c) não implantado }(0->50 \%)\end{array}$ \\
\hline 4. Remuneração de acordo com critérios estabelecidos & $\begin{array}{l}\text { a) vinculação da remuneração ao critério de desempenho } \\
\text { b) vinculação da remuneração ao critério de qualidade }\end{array}$ \\
\hline 5. Data base das categorias profissionais & $\begin{array}{l}\text { a) instituída } \\
\text { b) não instituída }\end{array}$ \\
\hline 6. Organização do banco de dados de pessoal & $\begin{array}{l}\text { a) organizado } \\
\text { b) utilizado como ferramenta gerencial } \\
\text { c) inexistência de banco de dados }\end{array}$ \\
\hline
\end{tabular}

\section{Análise de contexto}

Adespeito deasfundações exibirem desempenhosatisfatórionagestãodotrabalho, fatores específicos ou interação entre eles no macro e no microcontexto incidiram de forma diversa tanto na Bahia como em Sergipe, condicionando os resultados encontrados nas respectivas fundações (Quadro 4).

Assim, na Bahia, na análise da subdimensão da esfera política do macrocontexto, observou-se que, após um longo período de forças políticas de perfil conservador, a fundação estatal foi implantada em 2007 em uma conjuntura marcada pelo ingresso de forças políticas democráticas no cenário estadual e por mobilização em torno da reabertura de canais de participação da sociedade civil nos espaços de decisões do governo, como confirmado nas falas dos entrevistados a seguir:

Forças políticas de feitio mais conservador contrárias ao SUS durante longo período de governo (E3).

[...] Bahia tinha um quadro um pouco diferente do restante do Brasil [...] graças à permanência durante muitos anos, aqui, do ex-governador Antônio Carlos Maga-Ihães [...] (E10). 
Eleições deforças democráticasnoestadoemunicípios[proporcionaram]ambientes favoráveis a uma proposta de mudança aqui na Bahia (E12).

A apreciação das dimensões do macrocontexto indicou condições favoráveis e desfavoráveis à institucionalização da Funesa. Entretanto, a influência mútua entre as subdimensões das esferas política, econômica e social tornou exequível a sua implementação (Quadro 4).

Na gestão do trabalho, a inter-relação do microcontexto com subdimensões do macrocontexto contribuiu favoravelmente para a implementação das fundações, especialmente perante as dificuldades de captação, fixação, remuneração e formação dos profissionais da atenção básica na maioria dos municípios dos estados, o que se evidenciou nos argumentos dos interlocutores e na análise documental e fala dos entrevistados.

[...] contratação de profissionais, especialmente médicos pro Programa de Saúde da Família [...] (E1).

[...] criar uma lógica de uma remuneração não predatória (E3).

[...] viabilização de carreira, desprecarização e fixação dos profissionais (Bahia, 2009c).

Quadro 4.

\begin{tabular}{|c|c|c|c|c|c|c|}
\hline \multirow{3}{*}{ Componente } & \multicolumn{6}{|c|}{ Influência do macro e do microcontexto político-organizacional } \\
\hline & \multicolumn{3}{|c|}{ Fundação Estatal de Saúde da Família-Bahia } & \multicolumn{3}{|c|}{ Fundação Estadual de Saúde-Sergipe } \\
\hline & Grau & Favoráveis & Desfavoráveis & Grau & Favoráveis & Desfavoráveis \\
\hline $\begin{array}{l}\text { Gestão do } \\
\text { trabalho }\end{array}$ & 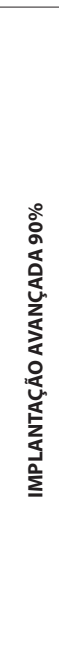 & $\begin{array}{l}\text { Esfera econômica } \\
\text { - Mudanças na } \\
\text { economia } \\
\text { Política setorial } \\
\text { - Principais interesses } \\
\text { - Poder dentro do setor } \\
\text { - Políticas de saúde } \\
\text { Finanças setoriais } \\
\text { - Orçamento e gastos } \\
\text { da saúde } \\
\text { - Políticas e mecanismos } \\
\text { de financiamento } \\
\text { - Fontes e volume de } \\
\text { recursos. } \\
\text { Problemas de saúde e } \\
\text { serviços } \\
\text { - Recursos humanos } \\
\text { - Rede de serviços de } \\
\text { saúde }\end{array}$ & $\begin{array}{l}\text { Esfera política } \\
\text { - Regime político } \\
\text { - Políticas públicas } \\
\text { Finanças } \\
\text { setoriais } \\
\text { - Orçamento e } \\
\text { gastos da saúde } \\
\text { - Políticas e } \\
\text { mecanismos de } \\
\text { financiamento } \\
\text { - Fontes e volume } \\
\text { de recursos } \\
\text { Problemas de } \\
\text { saúde e serviços } \\
\text { - Recursos } \\
\text { humanos }\end{array}$ & 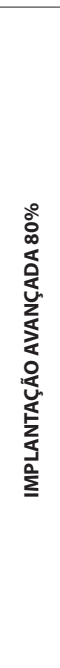 & 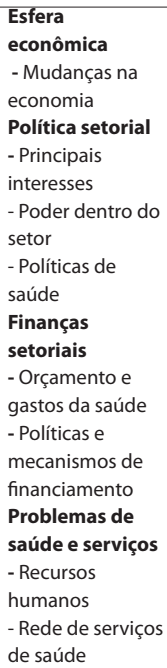 & $\begin{array}{l}\text { Finanças } \\
\text { setoriais } \\
\text { - Orçamento } \\
\text { e gastos da } \\
\text { saúde } \\
\text { - Políticas e } \\
\text { mecanismos de } \\
\text { financiamento } \\
\text { - Fontes e } \\
\text { volume de } \\
\text { recursos } \\
\text { Problemas } \\
\text { de saúde e } \\
\text { serviços } \\
\text { - Principais } \\
\text { problemas de } \\
\text { saúde } \\
\text { - Recursos } \\
\text { humanos }\end{array}$ \\
\hline
\end{tabular}




\section{Fundação estatal: contribuições para a gestão pública de saúde}

A implementação de fundações estatais na área da saúde é uma experiência relativamentenova, tendoemvistaoinícioefetivodefuncionamentoapenas em 2009 (Fesf, 2009), o que explica, em parte, a carência de estudos não só sobreofuncionamentocomotambémsobreasuaadequadaorganizaçãoem termos de recursos, estrutura e processos, necessários à realização dos objetivos de sua instituição.

Em um contexto de convivência de uma modelagem híbrida da administração pública brasileira, como apontado por Andion (2012), no qual se encontram resquícios das administrações burocrática, gerencial e nuances da societal (Paula, 2005), apresenta-se o desafio de superação dos limites impostos pelas características culturais, tais como o autoritarismo, o personalismo e o coronelismo.

Segundo Picchiai e Junqueira (2009), talvez a proposta das fundações estatais, por seus pressupostos de maior autonomia administrativa, instituição de processos de planejamento e avaliação, adoção de instrumentos mais ágeis e transparentes, assim como pela incorporação de inovações tecnológicas, possa se configurar em alternativa contribuindo com uma gestão pública de maior flexibilidade organizacional e gerencial, focalização em resultados e maior competência de decisão dos gestores.

Como observado por Andrade (2009), a criação da Fesf nasceu da necessidade de se responder aos problemas da Estratégia Saúde da Família na Bahia concernentes à precarização dos vínculos trabalhistas, entraves no provimento e fixação dos profissionais e incapacidade de formação e qualificação, que ocasionavam deformidades na execução das ações da referida estratégia. A admissão por meio de concurso ou seleção pública, a demissão motivada, a instituição de planos de desenvolvimento de pessoal e de carreira e salários, assim como a remuneração com base em critérios de desempenho e compatível com o praticado no mercado, são pressupostos para implantação das fundações visando à observância dos princípios e diretrizes organizacionais do SUS, sendo evidenciados em ambas as fundações estatais estudadas.

Confere-se à implantação da gestão por meio de contrato a possibilidade de reorganização da administração pública, em especial com relação ao aprimoramento dos métodos de controle. Para o ente público contratante, impõem-se um novo papel e a responsabilidade, ainda em aberto, de monitorar e avaliar as fundações estatais. No desenvolvimento dessa competência, é apontada como exigência a criação de estrutura organizacional de supervisão, com as atribuições de definir metas de desempenho, substituir a lógica de procedimento para a de resultados, instituir critérios profissionais para 
escolha dos dirigentes, garantir a democratização dos conselhos curadores, implantar sistema de monitoramento e avaliar resultados (Barboza, 2011).

A introdução da lógica de resultados com fixação de metas de desempenho pelas fundações estatais sugere a necessidade de mudanças, no sentido da qualidade e da efetividade nos processos de trabalho. Para tanto, exigese a adoção de um instrumento amparado legalmente e firmado por meio de pactuação entre o ente público e a fundação, o que pode possibilitar um modelo de gestão pública com maior autonomia, novos e eficientes mecanismos de prestação de contas e uma gestão do trabalho inovadora (Nogueira, 2007; Barboza, 2009).

Nesse sentido, o contrato de gestão assume a condição de ferramenta essencial para definição de objetivos, explicitação de metas e indicadores a serem observados na avaliação de desempenho e no acompanhamento dos serviços e processos realizados pelas fundações estatais. Revela ainda a importância da definição de um conjunto de indicadores quantitativos e qualitativos que integrarão o Plano Operativo de Atividades de modo a garantir o interesse público na contratação dos serviços (Schout e Rezende, 2009).

A iniciativa de implementação das fundações demandou maior presença dos gestores estaduais como indutores do processo. Apesar das particularidades, a conjuntura político partidária revelou-se como facilitadora à implementação das fundações nos dois estados.

Na análise dos atores, quando exibiam posição de apoio e estratégica acumulavam mais recursos de poder, se mostravam mais mobilizados e com disposição para alianças, contribuindo para a viabilidade da implantação das fundações. Aqueles com posição de rejeição ou de indiferença apresentavam restrito ou baixo acúmulo de poder, embora com capacidade de mobilização e de realizar alianças, limitando a viabilidade da implantação.

A apreciação das dimensões do macrocontexto da Fesf indicou condições favoráveis à sua implementação. No microcontexto, diversas situações culminaram com a instituição da fundação. Esteve presente a priorização da área da saúde, as questões relativas à gestão do trabalho (Bahia, 2009a) e os investimentos financeiros na atenção básica.

De modo semelhante, no microcontexto observou-se que a maioria de suas dimensões incorporava aspectos favoráveis à implementação da Funesa. Cooperaram para o alcance dos resultados as características e posições adotadas pelos atores.

Entretanto, os contextos incidiram de forma diversa tanto na Fesf como na Funesa. Na gestão do trabalho, a inter-relação do microcontexto com subdimensões do macrocontexto contribuiu favoravelmente para a implementação das fundações. Essas circunstâncias cooperaram para a realização de concurso público, instituição de planos de cargos e salários e de desenvolvimento de pessoal, remuneração com base em critérios de desempenho e qualidade, as- 
sim como a realização de cursos de pós-graduação (especialização em saúde da família e mestrado profissional em saúde pública na Fesf) - corroborando a afirmação de Matus (1996) de que um problema não pode ser apenas uma necessidade sentida, mas deve suscitar a ação.

As dificuldades na fixação, pela Fesf, da categoria médica na Estratégia Saúde da Família, relacionadas às características sistêmicas do mercado de trabalho no Brasil, manifestam-se como desafios às políticas públicas. Iniciativas estruturantes, tais como aumento de vagas nas escolas médicas, regulação das vagas para residência e ampliação de recursos para salários mais atrativos, são sugeridas por gestores e dirigentes das fundações (Fesf, 2013). Para Maciel Filho e Pierantoni (2013), o sistema de ensino e o modelo de atenção são fatores decisivos no ajustamento da demanda e composição da força de trabalho do médico no mercado.

O macrocontexto contribuiu, especialmente, com o poder de mobilização dos atores contrários à instituição das fundações nos dois estados - demonstrado por meio da recusa da representação de trabalhadores, coerente com as posições assumidas pelo movimento sindical no contexto de implantação das fundações. Como estratégia, a Fesf incorporou trabalhadores da própria fundação no Conselho Curador.

A singularidade de cada contexto denota a variedade de situações experimentadas pelas fundações. A ação direta de inconstitucionalidade impetrada contra a criação das fundações em Sergipe não fez parte do ambiente de implementação da Fesf.

Entretanto, similaridades também foram observadas como influência do contexto nos dois estados. Na implementação da Fesf e da Funesa, a conjuntura política contribuiu favoravelmente. As características dos atores estratégicos na defesa das fundações, como os governadores e secretários de saúde dos estados, exerceram papel decisivo para a implementação das fundações. As questões referentes à gestão do trabalho, consideradas desafios de grande magnitude e complexidade pelos gestores, também exibiram resultados satisfatórios nas duas fundações.

\section{Considerações finais}

O modelo de fundações estatais no sistema de saúde brasileiroé uma experiência nova, e o quadro aqui apresentado diz respeito às condições organizacionais e de contextos específicos dos dois estados. Ou seja, a singularidade de cada contexto expressa a variedade de situações experimentadas pelas fundações. Em Sergipe, uma ação direta de inconstitucionalidade foi impetrada contra a criação das fundações, situação não vivenciada no cenário de implementação da Fesf. 
Entende-se que as discussões em torno da instituição das fundações estatais, por incorporar um caráter estratégico sobre a reforma do Estado, ocorrem em contextos de intenso conflito, como aquele vivenciado em Sergipe, uma vez que a implementação das fundações esteve imersa no contexto de realização de uma reforma do próprio Estado.

No entanto, similaridades também foram observadas como influência do contexto nos dois estados relativas à conjuntura política favorável à implantação das fundações, assim como as características dos atores estratégicos, como governadores e secretários estaduais de saúde, na defesa das fundações.

Em que pese a constatação da baixa e até ausência da representação de usuários e trabalhadores das instâncias do SUS nos órgãos de direção das fundações, vale registrar a participação de trabalhadores das fundações nos seus conselhos curadores. A despeito de ainda serem escassas as avaliações científicas quanto aos resultados da governança pública, conclui-se pela necessidade não só de aprimoramento dos seus mecanismos por parte das fundações como também de novos formatos e dinâmicas institucionais, além de arranjos regulatórios inovadores entre Estado, mercado e sociedade civil.

A introdução da lógica de resultados com fixação de metas de desempenho pelas fundações estatais sugere a necessidade de mudanças no sentido da qualidade e efetividade do atendimento à população, assim como nos processos de trabalho e estruturas organizacionais. Para tanto, exige-se a adoção de um instrumento amparado legalmente e firmado por meio de pactuação entre o ente público e a fundação, o que pode possibilitar um modelo de gestão pública com maior autonomia, novos e eficientes mecanismos de prestação de contas e uma gestão inovadora de recursos humanos.

Entretanto, a instituição das fundações estatais aponta para a necessidade de mudanças da cultura organizacional, sob pena de se repetirem processos de gestão inadequados na nova estrutura. E ainda, a sustentabilidade financeira surge como consequência estrutural do próprio sistema de saúde.

O subfinanciamento da saúde, no Brasil, destoa das garantias constitucionais expressas nos princípios e diretrizes do SUS e impõem limites às iniciativas de profissionalização e aprimoramento da gestão pública de saúde. Por conseguinte, não se pretendeu ser abrangente em temática que incorpora grande complexidade como a gestão pública de saúde, mas tão somente oferecer um delineamento que auxilie na tomada de decisão dos gestores e dirigentes, como também promover novas contribuições para a realização de pesquisas que ampliem a compreensão do já disponível na área. Os resultados e potencialidades dessas experiências podem auxiliar no enfrentamento dos desafios à gestão em saúde, dotando-a de maior efetividade, celeridade e resolubilidade na atenção à saúde e na gestão do trabalho no SUS. 
Por fim, a título de sugestão para novas ponderações sobre inclusão das fundações estatais, recomendam-se estratégias e mobilizações que viabilizem a ampliação do financiamento do sistema de saúde brasileiro; a retomada do debate com a sociedade civil organizada nos espaços institucionais do SUS; a aprovação do projeto de lei complementar n. 92/2007; e a qualificação e a estruturação do sistema de gestão das secretarias estaduais e municipais de saúde para garantir o monitoramento e a avaliação das ações desenvolvidas pelas fundações.

\title{
LA RELACIÓN PÚBLICO-PRIVADO Y LA GESTIÓN DEL TRABAJO EN LAS FUNDACIONES ESTATALES DE SALUD
}

\begin{abstract}
Resumen Las discusiones sobre la relación público-privado enfatizan la necesidad de imprimir a la gestión pública más autonomía, agilidad y flexibilidad gerencialesy administrativas en sectores estratégicos del sistema de salud. La pesquisa cualitativa que dio origen a este artículo tuvo el objetivo de analizar la gestión del trabajo en la Fundación Estatal de Salud de la Familia de Bahia (Fundação Estatal de Saúde da Família da Bahia, en portugués) y en la Fundación Provincial de Salud de Sergipe (Fundação Estadual de Saúde de Sergipe, en portugués), usando la técnica de triangulación de datos y análisis hermenéutica-dialéctica. Participaron gestores, trabajadores y usuarios de los dos estados, totalizando veinte entrevistas semiestructuradas. Los factores contextuales y los actores han sido analizados utilizando un modelo que enfatizó las dimensiones del macro y del microcontexto. El desempeño satisfactorio relativo a la gestión del trabajo se puede atribuir a la variedad y complejidad de factores enfrentados por la administración directa. La interrelación delmicrocontextoconsubdimensiones delmacrocontextocontribuyófavorablemente para la implementación de las fundaciones. Como contribución a los gestores, se construyó un cuadro conteniendo indicadores para el monitoreo de las atribuciones da gestión del trabajo en las fundaciones estatales. Los resultadosy potencialidades de esas experiencias pueden ayudar en el enfrentamiento de los desafíos a la gestión en salud, dotándola de más efectividad, celeridad y resolubilidad en la atención a la salud y en la gestión del trabajo en el Sistema Único de Salud de Brasil.
\end{abstract}

Palabras clave gestión en salud; recursos humanos en salud; administración pública; asociación público-privada. 


\section{Colaboradores}

Reneide Muniz da Silva, Isabella Chagas Samico e Pedro Miguel dos Santos Neto contribuíram igualmente na concepção do projeto de pesquisa, análise e interpretação dos dados, redação e revisão crítica do manuscrito, aprovaram a versão final do artigo e responsabilizam-se integralmente pelo trabalho. Não há conflitos de interesses.

\section{Financiamento}

O presente artigo constitui um dos produtos da pesquisa Estratégias para regulação do trabalho em saúde nos diferentes modelos de gestão dos serviços públicos de saúde em estados da região Nordeste, realizada pela Estação Observatório de Recursos Humanos em Saúde do Centro de Pesquisas Aggeu Magalhães e financiada pelo Ministério da Saúde.

\section{Referências}

ABRUCIO, Fernando L. Reforma do Estado no federalismo brasileiro: a situação das administrações públicas estaduais. Revista de Administração Pública, Rio de Janeiro, v. 39, n. 2, p. 401-420, mar.-abr. 2005.

ANDION, Carolina. Por uma nova interpretação das mudanças de paradigma na administração pública. Cadernos Ebape.BR, Rio de Janeiro, v. 10, n. 1, p. 1-19, mar. 2012.

ANDRADE, Laíse R. A fé no SUS: fundação estatal como proposta de gestão do trabalho para a Estratégia Saúde da Família na Bahia. 128fls. Dissertação (Mestrado) Escola Nacional de Saúde Pública Sergio Arouca, Fundação Oswaldo Cruz, Rio de Janeiro, 2009.
ARAÚJO JÚNIOR, José L. C.; MACIEL FILHO, Rômulo. Developing an operational framework for health policy analysis. Revista Brasileira de Saúde Materno Infantil, Recife, v. 1, n. 3, p. 203-221, 2001.

ASSIS, Marluce M. A.; JORGE, Maria S. B. Métodos de análise em pesquisa qualitativa. In: SANTANA, Judith S. S.; NASCIMENTO, Maria A. A. (orgs.). Pesquisa: métodos e técnicas de conhecimento da realidade social. Feira de Santana: Universidade Estadual de Feira de Santana, 2010. p. 139-159. 
BAGATTOLLI, Carolina. Reforma do Estado: críticas ao modelo gerencial. Campinas: Departamento de Análise de Políticas de Inovação/Grupo de Análise de Políticas de Inovação/Universidade Estadual de Campinas (DAPI/GAPI/Unicamp), 2009. Disponível em: $<$ https://docplayer.com.br/16344401-Reformado-estado-criticas-ao-modelo-gerencial.html>. Acesso em: 22 jul. 2019.

BAHIA. Estatuto da Fundação Estatal Saúde da Família. Salvador: Fesf, 2009a.

BAHIA. Secretaria da Saúde do Estado da Bahia. Plano Estadual de Saúde: 2007-2010, vigência 2011. Revista Baiana de Saúde Pública, Salvador, v. 33, supl. 1, p. 76, 2009 b.

BAHIA. Fundação Estatal Saúde da Família. Prestação de contas originárias anual: relatório de gestão 2009. Salvador: Fesf-SUS, 2009c.

BARBOZA, Pedro. Fundações e modelos de gestão. Debates FGVsaúde, São Paulo, v. 7, p. 8-10, 2009.

BARBOZA, Pedro. Entrevistas em novembro de 2006 e abril e novembro de 2007. Rio de Janeiro: Escola Nacional de Saúde Pública Sergio Arouca, Fundação Oswaldo Cruz, 2011. Disponível em: <www5.ensp.fiocruz. br/biblioteca/dados/arq6837.ppt>. Acesso em: 23 abr. 2015.

BRASIL. Presidência da República. Decretolei n. 200, de 25 de fevereiro de 1967. Dispõe sobre a organização da administração federal, estabelece diretrizes para a reforma administrativa e dá outras providências. Diário Oficial da União, Brasília, DF, 27 fev. 1967. Seção 1, supl., p. 4.

BRASIL. Presidência da República. Lei $n$. 9.637, de 15 de maio de 1998. Dispõe sobre a qualificação de entidades como organizações sociais, a criação do Programa Nacional de Publicização, a extinção dos órgãos e entidades que menciona e a absorção de suas atividades por organizações sociais, e dá outras providências. Diário Oficial da República Federativa do Brasil, Poder Executivo, Brasília, DF, 18 maio
1998. Disponível em: <http://www.planalto. gov.br/ccivil_03/leis/l9637.htm>. Acesso em: 10 dez. 2014.

BRASIL. Ministério da Saúde. Secretaria Executiva. Departamento de Apoio à Descentralização. Gestores do SUS: olhares e vivências. Brasília: Ministério da Saúde, 2006. (Série C. Projetos, programas e relatórios).

BRASIL. Câmara dos Deputados. Projeto de lei complementar n. 92, de 4 de junho de 2007. Regulamenta o inciso XIX do art. 37 da Constituição Federal, parte final, para definir as áreas de atuação de fundações instituídas pelo poder público. Brasília: Câmara dos Deputados, 2007. Disponível em: <http://www. camara.gov.br/proposicoesWeb/fichadetram itacao?idProposicao=360082 > . Acesso em: 23 nov. 2011.

BRESSER-PEREIRA, Luiz C. Democracia, estado social e reforma gerencial. Revista de Administração de Empresas, São Paulo, v. 50, n. 1, p. 112-116, jan.-mar. 2010.

CENTRO BRASILEIRO DE ESTUDOS DE SAÚDE (CEBES). Necessidade de reformar a estrutura administrativa do gerenciamento público dos estabelecimentos públicos de prestação de serviços de saúde. In: SANTOS, Nelson R.; AMARANTE, Paulo (orgs.). Gestão pública e relação público-privado na saúde. Rio de Janeiro: Cebes, 2010. p. 320-324. Disponível em: <http://idisa.org.br/img/File/GC-2010RL-LIVRO\%20CEBES-2011.pdf>. Acesso em: 22 jul. 2019.

CHAMPAGNE, Jean-Louis D. F. et al. A análise de implantação. In: BROUSSELLE, Astrid et al. (orgs.). A avaliação: conceitos e métodos. Rio de Janeiro: Editora Fiocruz, 2011. p. 217-238.

CORREIA, Maria V. C. Por que ser contra aos novos modelos de gestão no SUS? In: BRAVO, Maria I. S.; MENEZES, Juliana B. (orgs.). Cadernos de Saúde: políticas sociais, saúde e participação na atualidade. Rio de Janeiro: Uerj, Rede Sirius, 2011. p. 43-49. 
COSTA, Frederico L. Condicionantes da reforma do Estado no Brasil. In: MARTINS, Paulo E. M.; PIERANTI, Octavio P. (orgs.). Estado e gestão pública: visões do Brasil contemporâneo. Rio de Janeiro: FGV, 2006. p. 133-158.

FONTES, Katiene C. A fundação hospitalar de saúde na SES de Sergipe e as estratégias de gestão do trabalho: examinando o caso do hospital de urgência de Sergipe. 107fls. Dissertação (Mestrado) - Escola Nacional de Saúde Pública Sergio Arouca, Fundação Oswaldo Cruz, Rio de Janeiro, 2009.

FRANZESE, Cibele. Federalismo cooperativo no Brasil: da Constituição de 1988 aos sistemas de políticas públicas. $210 f l s$. Tese (Doutorado em Administração Pública e Governo) - Escola de Administração de Empresas de São Paulo, Fundação Getúlio Vargas, São Paulo, 2010.

FUNDAÇÃO ESTATAL DE SAÚDE DA FAMÍLIA (FESF). Ata da 1a Reunião Ordinária. Salvador: Conselho Curador da Fesf, 2009.

FUNDAÇÃO ESTATAL DE SAÚDE DA FAMÍLIA (FESF). Prestação de contas ordinárias anual: relatório de gestão exercício de 2012. Salvador: Fesf, 2013.

HEIMANN, Luísa S. et al. A relação públicoprivado e o pacto pela saúde: novos desafios para a gestão em saúde? In: SANTOS, Nelson R.; AMARANTE, Paulo D. C. (orgs.). Gestão pública e relação público-privado na saúde. Rio de Janeiro: Cebes, 2010. p. 208-219.

LAMARCA, Isabel C. S. A. Reformas administrativas e políticas de incorporação da força de trabalho no governo central brasileiro, 1995-2006. 139fls. Tese (Doutorado) - Escola Nacional de Saúde Pública Sergio Arouca, Fundação Oswaldo Cruz, Rio de Janeiro, 2009.

LYRA, Tereza M. A política de saúde ambiental do Recife em 2001 e 2002: uma análise a partir do Programa de Saúde Ambiental. 300 fls. Tese (Doutorado em Saúde Pública) - Centro de Pesquisas Aggeu Magalhães, Fundação Oswaldo Cruz, Recife, 2009.
MACIEL FILHO, Rômulo; PIERANTONI, Célia R. O médico e o mercado de trabalho em saúde no Brasil, revendo conceitos e mudanças. Observatório de Recursos Humanos em Saúde no Brasil: estudos e análises, Brasília, v. 2, p. 139-162, 2013.

MATUS, Carlos. Política, planejamento e governo. 2. ed. Brasília: Ipea, 1996. v. 2.

MINAYO, Maria C. S. O desafio do conhecimento: pesquisa qualitativa em saúde. 8 . ed. São Paulo: Hucitec, 2004.

MINAYO, Maria C. S. Análise qualitativa: teoria, passos e fidedignidade. Ciência \& Saúde Coletiva, Rio de Janeiro, v. 17, n. 3, p. 621-626, 2012.

MÜLLER NETO, Júlio S. (org.). Regionalização da saúde em Mato Grosso: em busca da integralidade da atenção. Cuiabá: Secretaria de Estado de Mato Grosso, 2002.

NOGUEIRA, Roberto P. Composição público versus privado, gestão de unidades e recursos humanos no SUS. Brasília: UnB, 2007.

NOGUEIRA, Roberto P. O desenvolvimento federativo do SUS e as novas modalidades institucionais de gerência das unidades assistenciais. In: SANTOS, Nelson R.; AMARANTE, Paulo D. C. (orgs.). Gestão pública e relação público-privado na saúde. Rio de Janeiro: Cebes, 2010. p. 24-47.

ORGANIZAÇÃO DAS NAÇÕES UNIDAS PARA A EDUCAÇÃO, A CIÊNCIA E A CULTURA (UNESCO). Estudo sobre a contratualização hospitalar no âmbito do SUS. Rio de Janeiro: Fundação Getúlio Vargas, 2008.

PAULA, Ana P. P. Administração pública brasileira entre o gerencialismo e a gestão social. Revista de Administração de Empresas, São Paulo, v. 45, n. 1, p. 36-49, jan.-mar. 2005.

PICCHIAI, Djair; JUNQUEIRA, Luciano A. P. Fundação estatal e alternativas organizacionais para a área da saúde. Cadernos FGV Projetos, Rio de Janeiro, v. 9, p. 47-52, 2009. 
RIO DE JANEIRO (ESTADO). Lei n. 5.164, de 17 de dezembro de 2007. Autoriza o poder executivo a instituir a Fundação Estatal dos Hospitais Gerais, a Fundação Estatal dos Hospitais de Urgência e a Fundação Estatal dos Institutos de Saúde e da Central Estadual de Transplante, e dá outras providências. Disponível em: <https://gov-rj.jusbrasil.com. br/legislacao/87814/lei-5164-07>. Acesso em: 19 maio 2019.

SANTOS, Lenir. Administração pública e a gestão da saúde. In: SANTOS, Nelson R.; AMARANTE, Paulo D. C. (orgs.). Gestão pública e relação público-privado na saúde. Rio de Janeiro: Cebes, 2010. p. 68-86.

SANTOS, Nelson R. Sistema Único de Saúde - 2010: espaço para uma virada. O Mundo da Saúde, São Paulo, v. 34, n. 1, p. 8-19, 2010.

SCHOUT, Denise; REZENDE, Wilson. Contratos de gestão e sistema de indicadores de desempenho. Cadernos FGV Projetos: gestão e saúde, Rio de Janeiro, n. 9, p. 42-46, 2009.

SERGIPE. Assembleia Legislativa do Estado. Lei n. 6.346, de 2 de janeiro de 2008. Dispõe sobre a autorização para criação da Fundação de Saúde Parreiras Horta - FSPH - e dá providências correlatas. Diário Oficial do Estado, Aracaju, n. 25.424, 3 jan. 2008a.

SERGIPE. Assembleia Legislativa do Estado. Lei n. 6.347, de 2 de janeiro de 2008. Dispõe sobre a autorização para criação da Fundação Hospitalar de Saúde - FHS - e dá providências correlatas. Diário Oficial do Estado, Aracaju, n. 25.424, 3 jan. 2008b.

SERGIPE. Assembleia Legislativa do Estado. Lei n. 6.348, de 2 de janeiro de 2008. Dispõe sobre a autorização para criação da Fundação Estadual de Saúde (Funesa) e dá providências correlatas. Diário Oficial do Estado, Aracaju, n. $25.424,3$ jan. $2008 c$.

SERGIPE. Secretaria de Estado da Saúde. Estatuto da Fundação Estadual de Saúde (Funesa). Aracaju: Funesa, 2008d.

SILVA, Ligia M. V. Conceitos, abordagens e estratégias para a avaliação em saúde: aspectos conceituais e operacionais. In: HARTZ, Zulmira M. A.; SILVA, Ligia, M. V. (orgs.). Avaliação em saúde: dos modelos teóricos à prática na avaliação de programas e sistemas de saúde. Rio de Janeiro: Editora Fiocruz, 2005. p. 15-39.

TORRES, Marcelo D. F. Estado, democracia e administração pública no Brasil. Rio de Janeiro: Editora FGV, 2008.

VECINA NETO, Gonzalo. Formas jurídicas das organizações de saúde. Debates FGVsaúde, São Paulo, n. 7, p. 4-7, 2009.

YIN, Robert K. Estudo de caso: planejamento e métodos. 3. ed. Porto Alegre: Bookman, 2005. 